\title{
Final Technical Report for the MIT Annular Fuel Research Project
}

\author{
Sponsor: $\quad$ United States Department of Energy \\ Award Number: $\quad$ DE-FG07-01SF22329 \\ Awardee: $\quad$ Massachusetts Institute of Technology \\ Project Title: $\quad$ High Performance Fuel Design for Next Generation PWRs \\ Project Performance Period: 8/1/2001 through 10/31/2007
}

\author{
Professor Mujid S. Kazimi, Principal Investigator \\ KEPCO Professor of Nuclear Engineering \& Mechanical Engineering \\ Director, Center for Advanced Nuclear Energy Systems (CANES) \\ Massachusetts Institute of Technology \\ Building 24-219 \\ 77 Massachusetts Avenue \\ Cambridge, MA 02139-4307 \\ Tel 617-253-4206 \\ Fax 617-258-8863 \\ Email kazimi@mit.edu
}

January 31, 2008

The annular fuel research project was carried out during the period 8/1/2001 through 12/31/2005. A final report for this research project was previously submitted in January of 2006; the executive summary is appended at the end of this final report.

Following completion of the research project, a no-cost extension period was granted to allow for return of spent fuel and formal publication of the annular fuel research project results. No arrangements were concluded for return of spent fuel to DOE.

Professor Mujid S. Kazimi and Dr. Pavel Hejzlar, principal research scientist on this project, reviewed the proofs of all the papers written during the no-cost period \& approved same for publication. The papers developed were for publication in a special Annular Fuel Issue of the American Nuclear Society (ANS) journal, Nuclear Technology. The annular fuel special issue was devoted entirely to evaluation of a new fuel design for the pressurized water reactor (PWR). 
The papers listed below were published in Nuclear Technology, October, 2007, Vol. 160, No. 1. 1. "Annular Fuel for High-Power-Density Pressurized Water Reactors: Motivation and Overview"

Authors: Pavel Hejzlar, Mujid S. Kazimi

2. "Thermal-Hydraulic Design of High-Power-Density Annular Fuel in PWRs" Authors: Dandong Feng, Pavel Hejzlar, Mujid S. Kazimi

3. "Safety Analysis of High-Power-Density Annular Fuel for PWRs" Authors: Dandong Feng, Paolo Morra, Ramu Sundaram (Areva NP), Won-Jae Lee (KAERI), Pradip Saha, Pavel Hejzlar, Mujid S. Kazimi

4. "High-Performance Annular Fuel Reactor Physics and Fuel Management" Authors: Zhiwen Xu, Yasuyuki Otsuka, Pavel Hejzlar, Mujid S. Kazimi, Michael J. Driscoll

5. "Fertile-Free Annular Fuel for Plutonium Recycling" Authors: Eugene Shwageraus (Ben Gurion University), Pavel Hejzlar, Mujid S. Kazimi

6. "High-Power-Density Annular Fuel: Manufacturing Viability" Authors: Edward Lahoda, (Westinghouse), Herbert Feinroth, (Gamma Engineering), Marcelo Salvatore, (Invap), Diego O. Russo, (CNEA), Holly Hamilton, (Invap)

7. "High-Power-Density Annular Fuel for Pressurized Water Reactors: Manufacturing Costs and Economic Benefits"

Authors: Edward Lahoda, Jason Mazzoccoli, Julien Beccherle

8. “Thermomechanical Performance of High-Power-Density Annular Fuel” Authors: Yi Yuan, M. S. Kazimi, P. Hejzlar

9. "Irradiation Testing of High-Power-Density Vibropacked Annular Fuel” Authors: Gordon Kohse, David Carpenter, Yi Yuan, Pavel Hejzlar, Mujid Kazimi 
NUCLEAR FUEL CYCLE TECHNOLOGY AND POLICY PROGRAM

Nuclear Energy Research I nitiative (NERI) Project 01-005

\title{
High Performance Fuel Design for Next Generation PWRs: Final Report
}

Project DE-FG07-01SF22329

\author{
Principal I nvestigator: M.S. Kazimi \\ Co-Principal I nvestigator: P. Hejzlar \\ MI T-NFC-PR-082 \\ J anuary 2006
}

CONTRI BUTORS:

MIT

David Carpenter

Dandong Feng

Pavel Hejzlar

Mujid S. Kazimi

Gordon Kohse

Won-Jae Lee

Paolo Morra

Hee Cheon No

Yakov Ostrovsky

Yasuyuki Otsuka

Pradip Saha

Eugene Shwageraus

Zhiwen Xu

Yi Yuan

Jiyun Zhao

\author{
Gamma Engineering Corp. \\ Herbert Feinroth \\ Bernard Hao \\ Westinghouse Electric Co. \\ Edward J. Lahoda \\ Jason Mazzoccoli \\ In cooperation with Westinghouse: \\ Marcelo Salvatore (I NVAP) \\ Diego O. Russo (CNEA) \\ Framatome ANP \\ Ramu K. Sundaram \\ Atomic Energy of Canada Ltd. \\ Holly Hamilton
}




\section{Participating Organizations}

\section{Massachusetts Institute of Technology}

77 Massachusetts Ave., Cambridge, MA 02139

Prof. Mujid S. Kazimi

Telephone: (617) 253-4206; Fax: (617) 258-8863

kazimi@mit.edu

\section{Gamma Engineering Corporation}

15815 Crabbs Branch Way

Rockville, MA 20855

Mr. Herbert Feinroth

Telephone: (301) 840-8415; Fax: (301) 840-1479

feinroth@gamma-eng.com

Westinghouse Electric Corporation

Westinghouse Science \& Technology Department

1344 Beulah Rd.

Pittsburgh, PA 15235-5083

Dr. Edward J. Lahoda

Telephone: (412) 256-2238; Fax: (412) 256-1190

lahodaej@westinghhouse.com

\section{Framatome ANP}

400 Donald Lynch Boulevard

Marlborough, MA 01752

Dr. Ramu K. Sundaram

Telephone: (978) 568-2125; Fax: (978) 568-3704

Ramu.Sundaram@framatome-anp.com

Atomic Energy of Canada Limited

Chalk River Laboratories

Chalk River, Ontario, Canada K0J 1J0

Holly Hamilton

Telephone: (613) 584-3311, Ext. 6049; Fax: (613) 584-8158

hamiltoh@aecl.ca 


\section{EXECUTIVE SUMMARY}

This summary provides an overview of the results of the U.S. DOE funded NERI (Nuclear Research Energy Initiative) program on development of the internally and externally cooled annular fuel for high power density PWRs. This new fuel was proposed by MIT to allow a substantial increase in power density (on the order of $30 \%$ or higher) while maintaining or improving safety margins. A comprehensive study was performed by a team consisting of MIT (lead organization), Westinghouse Electric Corporation, Gamma Engineering Corporation, Framatome ANP (formerly Duke Engineering) and Atomic Energy of Canada Limited. The study involved the evaluation of the new fuel in terms of thermal hydraulic, neutronics, fuel performance including first scoping irradiation tests at the MIT reactor, fuel manufacturing and economics.

The proposed fuel is of annular shape and has both internal and external cooling, as shown in Figure ES-1. To provide sufficient flow rate through the inner cooling channel, significantly larger rod size than the typical fuel rods of 17x17 PWR fuel arrays has to be employed. Therefore, for a fixed assembly size, the PWR fuel assembly has a smaller number of annular fuel rods.

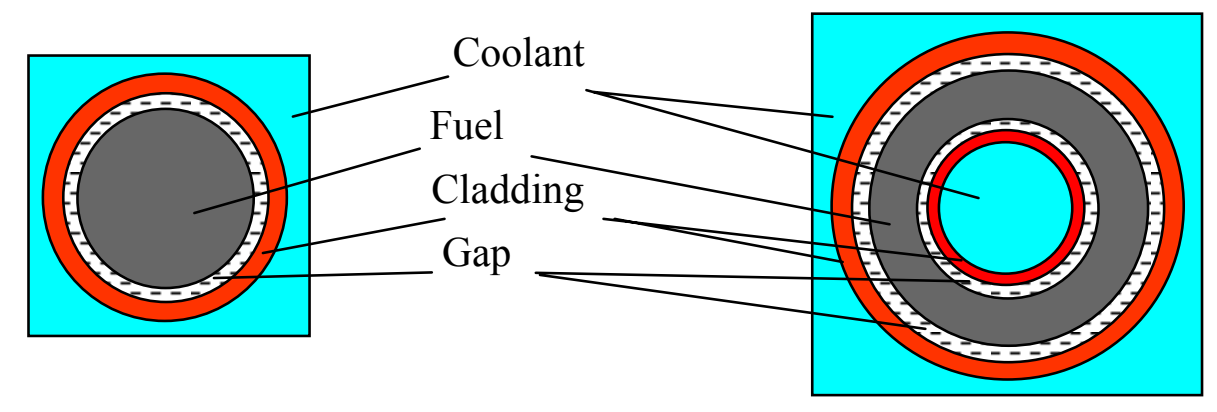

Figure ES-1 Schematic of solid and internally and externally cooled annular fuel (not to scale)

A transition from solid to annular geometry has two important implications that allow power density increases: (1) reduction of conduction path thickness, which improves margin from peak fuel temperature to melting and (2) increased heat transfer surface area (in spite of a reduction of the number of fuel rods), which improves the margin for Departure from Nucleate Boiling Ratio (DNBR).

The overall objective of this NERI project was to examine the potential for improving safety and economics of pressurized water reactors (PWRs) through a high-performance externally and internally cooled annular fuel. This has been pursued through the following tasks:

1. Identify the most promising fuel assembly arrangement for PWRs to achieve a significant increase in power density of at least 30 percent; based to a large extent on the extensive PWR $\mathrm{UO}_{2}$ fuel database to minimize R\&D development expenses and the risks associated with transition to a new fuel materials. 
Optimize the fuel for superior thermal hydraulic performance. Examine flow distribution, core pressure drop, departure from nucleate boiling ratio (DNBR), and resistance to parallel channel instabilities.

2. Perform safety analyses, such as loss of coolant accident (LOCA) analyses, to confirm safety benefits for the optimum configuration identified in item (1).

3. Evaluate the neutronic fuel design to achieve high reactivity-limited burn-up and a refueling cycle comparable to current PWR practice to attain good economic features. Confirm the acceptability of the coefficients for reactivity feedback and reactivity control.

4. Select fabrication processes to produce annular fuel elements with the required product characteristics, including fissile loading and high integrity cladding, which are capable of eventual scale-up into efficient production processes for economic and reliable fuel element performance.

5. Evaluate the materials and mechanical performance of $\mathrm{UO}_{2}$ fuel forms obtained by production technologies different from current U.S. practices (e.g., vibropacked fuel), and operating under new conditions (such as very low fuel temperature). Develop models for assessing fuel performance as well as for scoping irradiation tests performed at the research reactor of Massachusetts Institute of Technology (MIT).

6. Estimate the economic cost or benefit in cases of using the annular fuel for uprating current Generation II PWRs or in new advanced PWRs.

Next, the key results and conclusions are summarized and guidelines as to in which chapters of this report contain more detailed analyses are provided.

\section{Thermal hydraulic performance}

The optimum square lattice annular fuel design that allows maximum power uprate was investigated using a VIPRE-01whole core model. The VIPRE-01 methodology for the analysis of fuel geometry with internal and external cooling was developed. Various square array sizes $(11 \times 11$ to $15 \times 15)$ that fit in the fixed dimensions of a fuel assembly were explored. The most promising options, based on DNBR considerations, were found to be the $13 \times 13$ and $12 \times 12$ arrays with the dimensions shown in Table ES-1. Because fuel performance modeling results showed that thermal expansion and swelling of fuel pellets during operation are towards the outer cladding, the heat flux to the outer channel may increase. The $13 \times 13$ array accommodates higher heat flux to the outer channel, thus the $13 \times 13$ array was selected as the most promising design. 
The $13 \times 13$ design allows a power uprate of $50 \%$ in terms of DNBR limit*, if the flow rate is increased proportionally. This is a significant power uprate, raising the extracted power from the same core size to support increasing the plant output from the current $1150 \mathrm{MWe}$ to $1750 \mathrm{MWe}$. The same power uprate capability was also shown to be possible for the largest currently available reactor coolant pumps, which deliver flow rates limited to 130 percent, if the core inlet temperature is reduced by $10^{\circ} \mathrm{C}$. Similar power uprates with annular fuel were found possible for the hexagonal lattice cores typical of Russian VVER reactor designs. At such high power, the peak fuel temperature is still about $1300^{\circ} \mathrm{C}$ lower than the reference solid fuel, as shown in Figure ES- 2.

Table ES-1 Dimensions (cm) of annular fuel elements of optimum arrays and the reference solid fuel array

\begin{tabular}{|l|c|c|c|c|c|c|c|}
\hline Array & $\mathrm{D}_{\text {cii }}$ & $\mathrm{D}_{\text {cio }}$ & $\mathrm{D}_{\text {fi }}$ & $\mathrm{D}_{\text {fo }}$ & $\mathrm{D}_{\mathrm{ci}}$ & $\mathrm{D}_{\mathrm{co}}$ & Pitch \\
\hline $12 \times 12$ & 0.9533 & 1.0676 & 1.08 & 1.5400 & 1.5524 & 1.6667 & 1.789 \\
$13 \times 13$ & 0.8633 & 0.9776 & 0.99 & 1.4100 & 1.4224 & 1.5367 & 1.651 \\
$17 \times 17$-ref. & Solid pin & - & - & 0.8255 & 0.8379 & 0.9522 & 1.263 \\
\hline
\end{tabular}

"Subscripts, $c i, f$ and $c o$ designate inner cladding, fuel and outer cladding respectively; a second subscript designates outer (o) or inner (i) surface.

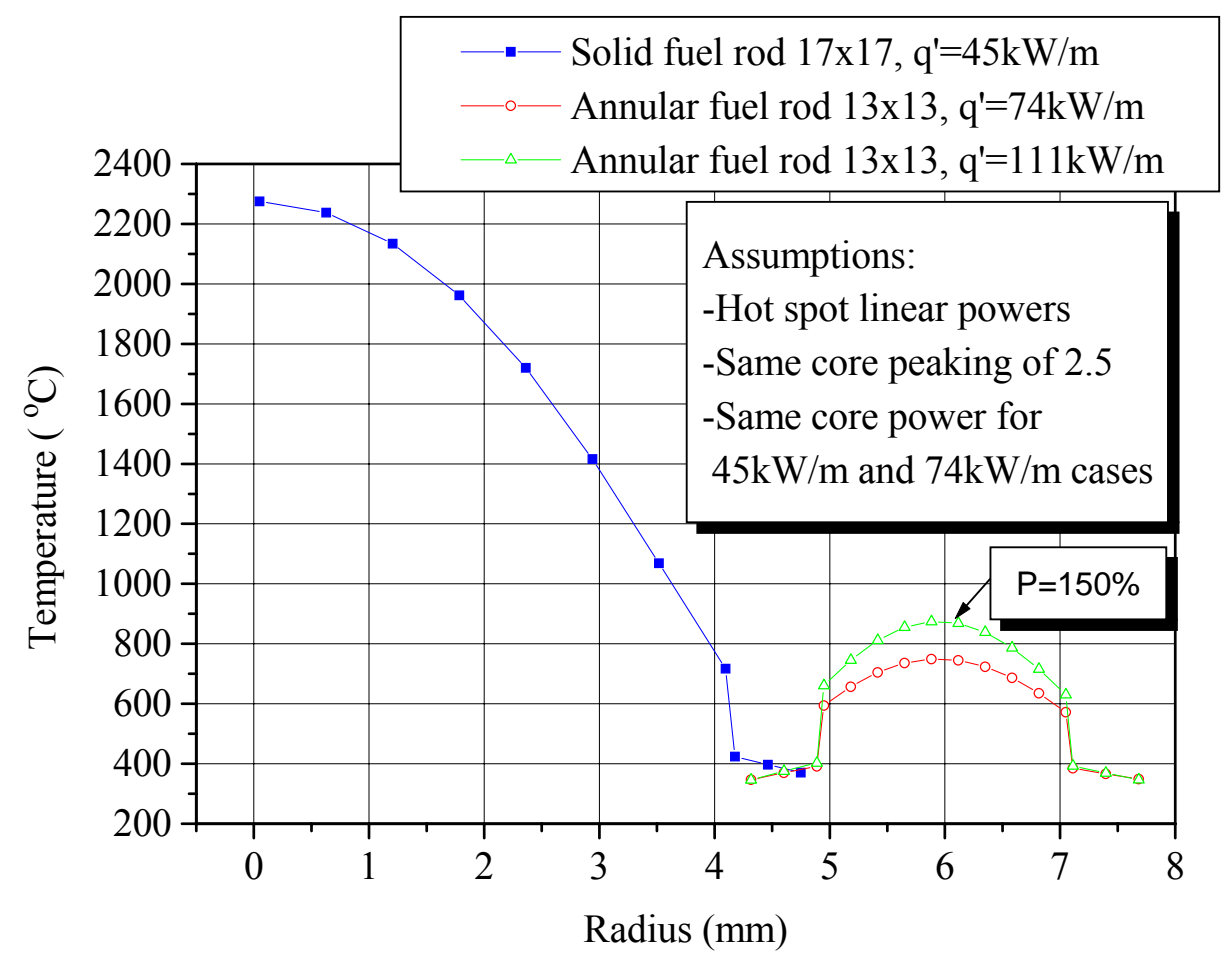

Figure ES-2. Comparison of hot-spot radial temperature profiles for solid and annular fuel

\footnotetext{
* Core with annular fuel operating at $150 \%$ power gives the same minimum DNBR as the reference core with solid fuel at $100 \%$ power.
} 
Such a high power uprate requires proportional increase of core flow rate resulting in a larger pressure drop and velocity, which in turn raises concerns about vibration and fuel assembly lift-off. To address vibration concerns at higher velocities, five flow-induced vibration mechanisms for the annular fuel rods were analyzed. Compared to the reference solid fuel, the annular fuel was found to exhibit, at $150 \%$ flow rate, better mechanical behavior with respect to vortex-induced vibration, fluid-elastic instability, and turbulentinduced vibrations than the reference solid fuel in a $17 \times 17$ lattice at $100 \%$ power. Also, fretting, sliding and impact wear were found to be smaller for annular fuel. Annular fuel benefits from smaller cross flow velocities and more importantly larger rigidity. Analysis of the buckling instability of the inner cladding, which lacks grid support, showed that the maximum stress in the inner cladding generated by the bending moment is small due to very limited cladding displacement constrained by the fuel and the outer grid-supported cladding. Evaluation of acoustic resonances of the inner channel cladding with pump blade passing frequencies showed that there is a need to slightly increase separation of the natural frequency from the pulsation frequency. This can be done either through natural frequency change by increasing the length of fuel pins or through a change in pulsation frequency. The latter can be achieved by lowering pump speed or the number of blades. Overall, the proposed annular fuel design was found to be more resistant to the above vibration modes and vibration issues do not pose a limit to power and flow rate increase of 50\%. However, lift-off forces are several times higher than for the reference fuel and will require design modifications of the fuel assembly and fuel rod holding mechanism. Details on mechanical design are in Chapter 8.

Because parallel non-communicating channels are more susceptible to various thermohydraulic instability phenomena than communicating channels, flow instability concerns were addressed. Two major instability types - excursive (Ledinegg) instability and density wave oscillations - were evaluated. No excursion type instabilities were observed and MDNBR was found more limiting than the flow excursion instability limit. The analysis of susceptibility to density wave oscillations confirmed that operation at $150 \%$ power is deeply in the stable region. Therefore, flow instability is not an issue for the proposed annular fuel, in spite of the fact that the internal channels are isolated and do not communicate with other channels. The high system pressure and the small channel fraction experiencing subcooled boiling with a small void fraction, are the main factors for operation far from the instability line.

Sensitivity calculations have shown that the MDNBR is more sensitive to manufacturing tolerances and oxide growth than the reference solid fuel, because of the absence of cross flow mass and enthalpy exchanges in the inner channels. Nevertheless, sensitivity results have also shown that MDNBR changes due to these effects are small and do not violate the MDNBR limit. In addition, annular fuel is more sensitive to operating parameters, such as core flow rate, core power, core inlet temperature and systems pressure. This larger sensitivity is compensated by the larger DNBR margin at rated conditions gained from the new geometry with larger heat transfer surface and higher mass flux. Finally, the concern about potential plugging of inner channel with debris was also investigated. Although total plugging of the inner channel does not lead to excessive fuel temperature, the inner cladding would be subjected to damaging temperatures, hence full plugging must be prevented. This can be easily achieved through the use of inlet debris filters, 
which are used in all current PWRs to minimize debris-induced fretting and have mesh passages smaller than the diameter of the inner channel.

In conclusion, steady thermal hydraulic calculations confirmed that the proposed annular fuel can achieve substantial power uprate up to $50 \%$ and no show stoppers were identified. Details of these thermal hydraulic studies are given in Chapter 6.

\section{Safety Analysis Performance}

Four accidents of the annular fueled PWRs were evaluated in a comparative manner against the reference PWR plant with traditional solid fuel. The accidents involved the Loss-of-Coolant Accident (LOCA), the Loss of Flow Accident (LOFA), the Main Steam Line Break (MSLB), and the Rod Ejection accident. To perform these analyses, RELAP5-3D/ATHENA was used, after proper models were developed.

To accommodate $50 \%$ higher decay heat during reheat period after LOCA, three options of safety injection (SI) and accumulator (ACC) systems have been explored involving $100 \%$ SI and $150 \%$ ACC, $150 \%$ SI and 100\% ACC and 150\% SI and 150\% ACC. The blowdown cladding temperature peak was eliminated for all cases even at $150 \%$ power because of very low stored energy in the fuel. The peak cladding temperatures from heatup remained well below the safety limit of $1200^{\circ} \mathrm{C}$ for all three cases, but for the case with $100 \%$ SI, the peak cladding temperature stayed at high values much longer than the other two cases before quenching. Therefore, SI at $150 \%$ capacity and the same accumulator size $(100 \%$ capacity) were selected for the $150 \%$ rated core. Overall, the analyses confirmed that the core at $150 \%$ power could withstand a LOCA without exceeding the cladding temperature limit.

The complete Loss of Flow Accident (LOFA) was analyzed using RELAP3D/ATHENA code and VIPRE-01 code. The results at $150 \%$ power show that the DNBR of annular fuel decreases faster than that of the reference solid fuel at $100 \%$ power, mainly due to its larger sensitivity to coolant flow rate. However, because the initial DNBR margin of annular fuel is significantly larger than for the solid fuel, the lowest value of MDNBR reached during the transient is slightly higher than that of the solid fuel. After reaching a minimum value, the MDNBR for annular fuel increases more rapidly than that of solid fuel due to the much smaller stored energy of annular fuel. The LOFA results confirmed the results of the steady-state MDNBR analyses at overpower, which showed the capability of annular fuel to operate at $150 \%$ power.

The Main Steam Line Break (MSLB) and Rod Ejection Events were analyzed for solid and annular fuel rods at $100 \%$ and $150 \%$ power levels. The MSLB results confirmed the expectations that the annular fuel operated at $150 \%$ power has sufficient MDNBR margins comparable to those of the solid fuel at $100 \%$. Also, the rod ejection results showed that the peak fuel temperature for the annular fuel would remain significantly below that for the solid fuel (about $1200^{\circ} \mathrm{C}$ versus $2200^{\circ} \mathrm{C}$ ). On the other hand, the temperature increase from steady state values was about $50 \%$ higher for the annular fuel due to higher power density and slightly smaller fuel volume. Nevertheless, the radial averaged fuel temperatures of annular fuel remains significantly lower than that of the solid fuel $\left(1150^{\circ} \mathrm{C}\right.$ versus $\left.1450^{\circ} \mathrm{C}\right)$. Correspondingly, the radial average fuel enthalpy at the axial location of the peak temperature is about $30 \%$ lower for the annular fuel than for 
the solid fuel. Therefore, the margins to fuel enthalpy limit is substantially higher for annular fuel in spite of its $50 \%$ higher power density.

In conclusion, the safety analysis results of the above four major accidents show satisfactory safety performance of annular fuel for power uprates up to $50 \%$. More details on safety analyses are given in Chapter 7.

\section{Neutronic performance}

The optimum dimensions of the internally and externally cooled annular fuel are primarily determined by thermal hydraulic analyses, which were performed under the constraint of maintaining the heavy metal to moderator ratio close to the reference value of the current solid fuel. Additional cladding volume is needed for the annular fuel, which reduces the volume available for the fuel and coolant. Hence, about $9 \%$ less heavy metal can be loaded in the core, which affects negatively the fuel cycle length. Nevertheless, the heavy metal to moderator ratio was preserved by correspondingly slight reduction of moderator volume. The smaller heavy metal loading and added cladding necessitate slightly higher enrichment, but this increase is minor in comparison with the enrichment increases needed to achieve $50 \%$ higher burnup as a result of large power uprate to maintain the cycle length of 18 months per current practice in most US plants. Therefore, the major challenge in the neutronic task was to design the core and its fuel management scheme such that it can achieve 18 month cycle length at 50\% higher power density with acceptable power peaking and other neutronic parameters. The design targets include assurance of core operation at a $90 \%$ capacity factor for an 18 -month cycle, maximum core boron concentration of $1750 \mathrm{ppm}$, maximum radial pin power peaking of 1.65 , and a hot spot factor of 2.5 .

Three cores were designed using the CASMO4/SIMULATE code package and a consistent methodology - a reference PWR core with solid fuel and two annular fueled cores, one operating at $100 \%$ power and the other at $150 \%$-power. This made possible a comparison between the annular-fueled cores and the reference core based on the same number of reload assemblies and the same set of design criteria. The generic annular core design philosophy followed the existing industrial 3-batch core. The 72 reload assemblies were subdivided into two enrichment levels: 48 with higher and 24 with lower enrichment. The sub-batch with higher enrichment stays in the core for 3 cycles whereas the lower-enriched fuel remains for 2 cycles, but at higher flux regions to achieve comparable burnup. The loading pattern of an equilibrium annular fueled core for $150 \%$ power rating is shown (with peaking and burnups) in Figure ES-3. The red, blue and grey colors indicate fresh, once-burnt and twice burnt fuel assemblies, respectively (corresponds to first number 0,1,2). The letters $\mathrm{H}$ and $\mathrm{L}$ designate high $(9.0 \%)$ and low $(8.1 \%)$ enrichment, the first two numbers after a letter stand for number of rods with gadolinium and the last two numbers designate $\mathrm{Gd} \mathrm{wt} \%$ in these rods (for example 80 stands for $8.0 \mathrm{wt} \%$ ).

Figure ES-3 shows that fuel assemblies are exposed to significantly high burnups, up to $102 \mathrm{MWd} / \mathrm{kg}$, although accumulated over the same 4.5 year core residence time as for the reference solid fuel. To extract $\sim 50 \%$ more energy per assembly requires a corresponding increase of enrichment. The $8.1 \%$ and $9.0 \%$ are well above the 5 w/o licensing limit of 
most manufacturing plants, hence a transition to this annular high power density fuel would require changes in fuel manufacturing plants. However, if heavier uranium compounds can be considered, e.g., uranium nitride, and the number of reload assemblies can be increased, the fuel enrichment can be limited within 5 w/o. Higher enrichment hardens the neutron spectrum and as a consequence reduces the reactivity worth of control materials. Satisfying the limit on core boron concentration implies more burnable poison usage in the fresh fuel. The management of the power distribution through the entire cycle while ensuring acceptable burnable poison residue becomes more challenging. The shutdown margin is also slightly reduced based on the existing Ag-In$\mathrm{Cd}$ control rod system and requires stronger control materials.

\begin{tabular}{|c|c|c|c|c|c|c|c|}
\hline $\mathrm{H}$ & $G$ & $F$ & $E$ & $D$ & C & $B$ & $A$ \\
\hline $\begin{array}{c}\text { L2410 } \\
0.968 \\
1.001 \\
94.289 \\
\end{array}$ & $\begin{array}{c}\text { OL2410 } \\
1.350 \\
1.470 \\
36.666\end{array}$ & $\begin{array}{c}1 \mathrm{~L} 2880 \\
1.124 \\
1.175 \\
73.573 \\
\end{array}$ & $\begin{array}{c}\text { OL2880 } \\
1.313 \\
1.422 \\
38.982\end{array}$ & $\begin{array}{c}2 \mathrm{H} 2880 \\
0.947 \\
0.988 \\
102.349\end{array}$ & $\begin{array}{c}\mathrm{OH} 2880 \\
1.334 \\
1.440 \\
41.055\end{array}$ & $\begin{array}{c}1 \mathrm{~L} 2410 \\
0.980 \\
1.111 \\
67.491 \\
\end{array}$ & $\begin{array}{c}2 \mathrm{H} 2880 \\
0.523 \\
0.740 \\
87.522\end{array}$ \\
\hline $\begin{array}{c}\text { OL2410 } \\
1.350 \\
1.470 \\
36.666\end{array}$ & $\begin{array}{c}2 \mathrm{H} 2880 \\
1.037 \\
1.091 \\
92.819\end{array}$ & $\begin{array}{c}\text { OL2880 } \\
1.332 \\
1.441 \\
38.588\end{array}$ & $\begin{array}{c}2 \mathrm{H} 2880 \\
1.028 \\
1.096 \\
89.111\end{array}$ & $\begin{array}{c}\mathrm{OH} 2880 \\
1.302 \\
1.412 \\
40.261\end{array}$ & $\begin{array}{c}1 \mathrm{~L} 2880 \\
1.051 \\
1.118 \\
73.400\end{array}$ & $\begin{array}{c}\mathrm{OH} 2880 \\
1.267 \\
1.425 \\
36.963\end{array}$ & $\begin{array}{c}1 \mathrm{H} 2880 \\
0.682 \\
0.969 \\
56.726\end{array}$ \\
\hline $\begin{array}{c}1 L 2880 \\
1.124 \\
1.175 \\
73.573\end{array}$ & $\begin{array}{c}\text { OL2880 } \\
1.332 \\
1.441 \\
38.581\end{array}$ & $\begin{array}{c}\mathrm{H} 2880 \\
1.004 \\
1.053 \\
93.549\end{array}$ & $\begin{array}{c}\text { OL3280 } \\
1.260 \\
1.369 \\
39.024 \\
\end{array}$ & $\begin{array}{c}2 \mathrm{H} 4060 \\
0.926 \\
1.018 \\
88.512 \\
\end{array}$ & $\begin{array}{c}1 \mathrm{H} 2880 \\
1.030 \\
1.116 \\
72.518\end{array}$ & $\begin{array}{c}\mathrm{OH} 2880 \\
1.259 \\
1.418 \\
37.033 \\
\end{array}$ & $\begin{array}{c}1 \mathrm{H} 4060 \\
0.665 \\
0.948 \\
56.883\end{array}$ \\
\hline $\begin{array}{c}\text { OL2880 } \\
1.313 \\
1.422 \\
38.982 \\
\end{array}$ & $\begin{array}{c}2 \mathrm{H} 2880 \\
1.028 \\
1.096 \\
89.077 \\
\end{array}$ & $\begin{array}{c}\text { OL3280 } \\
1.259 \\
1.367 \\
38.976 \\
\end{array}$ & $\begin{array}{c}1 \mathrm{H} 1660 \\
1.051 \\
1.182 \\
69.067 \\
\end{array}$ & $\begin{array}{c}1 \text { L3280 } \\
0.912 \\
0.962 \\
72.097 \\
\end{array}$ & $\begin{array}{c}1 \mathrm{H} 2460 \\
1.026 \\
1.112 \\
69.825 \\
\end{array}$ & $\begin{array}{c}\mathrm{OH} 2460 \\
1.127 \\
1.346 \\
34.212 \\
\end{array}$ & $\begin{array}{c}2 \mathrm{H} 2460 \\
0.423 \\
0.709 \\
81.499 \\
\end{array}$ \\
\hline $\begin{array}{c}2 \mathrm{H} 2880 \\
0.947 \\
0.988 \\
102.349\end{array}$ & $\begin{array}{c}\mathrm{OH} 2880 \\
1.302 \\
1.412 \\
40.259 \\
\end{array}$ & $\begin{array}{c}2 \mathrm{H} 4060 \\
0.925 \\
1.018 \\
88.548 \\
\end{array}$ & $\begin{array}{c}1 \mathrm{~L} 3280 \\
0.912 \\
0.962 \\
72.055 \\
\end{array}$ & $\begin{array}{c}1 \mathrm{H} 2880 \\
0.988 \\
1.084 \\
75.714 \\
\end{array}$ & $\begin{array}{c}\mathrm{OH} 4060 \\
1.222 \\
1.358 \\
37.698 \\
\end{array}$ & $\begin{array}{c}1 \mathrm{H} 2880 \\
0.726 \\
0.968 \\
62.357 \\
\end{array}$ & \\
\hline $\begin{array}{c}\mathrm{OH} 2880 \\
1.334 \\
1.440 \\
41.055\end{array}$ & $\begin{array}{c}1 \mathrm{~L} 2880 \\
1.051 \\
1.118 \\
73.390\end{array}$ & $\begin{array}{c}1 \mathrm{H} 2880 \\
1.030 \\
1.116 \\
72.519\end{array}$ & $\begin{array}{c}1 \mathrm{H} 2460 \\
1.026 \\
1.112 \\
69.864\end{array}$ & $\begin{array}{c}\mathrm{OH} 4060 \\
1.223 \\
1.359 \\
37.755\end{array}$ & $\begin{array}{c}\mathrm{OH} 1660 \\
1.072 \\
1.343 \\
32.279\end{array}$ & $\begin{array}{c}2 \mathrm{H} 2880 \\
0.395 \\
0.694 \\
86.882\end{array}$ & \\
\hline $\begin{array}{c}1 \mathrm{~L} 2410 \\
0.980 \\
1.111 \\
67.491\end{array}$ & $\begin{array}{c}\mathrm{OH} 2880 \\
1.267 \\
1.425 \\
36.957\end{array}$ & $\begin{array}{c}\mathrm{OH} 2880 \\
1.259 \\
1.417 \\
37.035\end{array}$ & $\begin{array}{c}\mathrm{OH} 2460 \\
1.127 \\
1.346 \\
34.243\end{array}$ & $\begin{array}{c}1 \mathrm{H} 2880 \\
0.729 \\
0.970 \\
62.465\end{array}$ & $\begin{array}{c}2 \mathrm{H} 1660 \\
0.413 \\
0.711 \\
80.672\end{array}$ & & \\
\hline $\begin{array}{c}2 \mathrm{H} 2880 \\
0.523 \\
0.740 \\
87.522\end{array}$ & $\begin{array}{c}\mathrm{H} 2880 \\
0.682 \\
0.969 \\
56.713\end{array}$ & $\begin{array}{c}1 \mathrm{H} 4060 \\
0.665 \\
0.947 \\
56.934\end{array}$ & $\begin{array}{c}2 \mathrm{H} 2460 \\
0.423 \\
0.709 \\
81.545\end{array}$ & $\begin{array}{l}\text { Fuel ID } \\
\text { Assembly } \\
\text { Peak pin } \\
\text { Assembly }\end{array}$ & $\begin{array}{l}\text { wer } \\
\text { ver } \\
\text { rnup }\end{array}$ & & \\
\hline
\end{tabular}

Figure ES-3: Assembly power distribution at EOC for the IXAF-fueled, 150\%-power core 
Reactivity feedback parameters were also evaluated for all three cores. The moderator temperature coefficient of the annular core is slightly more negative than for the solid core. The Doppler coefficient is about the same, but the lower initial temperature of the annular fuel provides larger margins for negative Doppler feedback in accidents with reactivity increase, and smaller reactivity penalty for zero to hot full power heat up.

The potential of plutonium burning in the high power density core with annular fuel was also explored. The annular fertile free Pu loaded fuel in a highly uprated core appears to be feasible, but power uprates are restricted to less than $50 \%$ because of relatively high power peaking and potential for slightly positive MTC at BOC. The results suggest that a power density increase of $40 \%$ should have the initial $\mathrm{Pu}$ loading sufficiently low to assure acceptable core power peaking and negative MTC at all times during the cycle. However, the need for a large amount of enriched burnable poisons makes the design of fertile-free $\mathrm{Pu}$ burning core economically unattractive. A more attractive option for management of the transuranic isotopes deserving evaluation in the future would be the COmbined Non-Fertile and UO2 (CONFU) fuel, which could be easily adapted for annular fuel.

Overall, the annular-fueled high power density cores showed comparable steady-state performance, including power distributions and reactivity coefficients, to the reference solid fuel core. Hence, the retrofittability of the new annular fuel appears to be technically feasible for the next generation high density PWRs from a reactor physics point of view. More details on reactor physics analyses are covered in Chapter 9.

\section{Fuel Fabrication Feasibility}

One of the major issues of any new fuel is the feasibility of its fabrication to high and stringent standards. Therefore, the important task of this project was focused on the evaluation, development, and laboratory-scale demonstration of selected, desirable fabrication processes of the annular fuel. Fuel fabrication feasibility study was performed in three phases. First, a broad based evaluation of the possible fabrication processes that are pertinent to the optimized annular fuel design were performed by Gamma Engineering. Potential fabrication routes and processing technologies of annular fuel elements that were evaluated included:

(1) Sintered ring pellet fabrication route with current commercial punch and die pressing technology for fabricating green pellets followed by sintering processing.

(2) Sintered ring pellets fabrication route with slurry extrusion technology for fabricating green pellets followed by drying and then sintering processing.

(3) Sintered ring pellets fabrication route with cold iso-static pressing technology for fabricating green ring pellets followed by sintering processing.

(4) VIPAC fuel element fabrication route with different particle size components of crushed high density sintered $\mathrm{UO}_{2}$ fuel material. 
(5) VIPAC fuel element fabrication route with different particle size components of spherical high density $\mathrm{UO}_{2}$ fuel material formed by special processes such as sol gel.

The sintered ring pellet (1) and VIPAC (4) fabrication technologies were selected as the most promising candidates for further evaluation.

In the second phase, analyses and development of the above most promising fuel fabrication technologies were pursued. The third phase covered laboratory-scale demonstration of the developed fabrication processes to provide near prototypical annular fuel rods with depleted uranium oxide for pertinent product characterization. The major results achieved for the sintered ring pellet and VIPAC processes are summarized below.

VIPAC fuel fabrication was performed at AECL. First, six $10 \mathrm{~cm}$ long annular fuel specimens with enriched uranium fuel were fabricated to be used at MITR for irradiation - see Figure ES-4. High density ( $>97 \%$ theoretical) crushed $4.91 \mathrm{wt} \%$ enriched sintered $\mathrm{UO}_{2}$ pellets were used as feed material. Due to the small annulus gap width for fuel material (i.e., $\sim 2 \mathrm{~mm}$ ), the optimum fuel feedstock was found to require two particle size components (i.e., $\sim 70 \mathrm{wt} \%$ of $0.25-0.50 \mathrm{~mm}$ granules and $\sim 30 \mathrm{wt} \% 0.025-0.053 \mathrm{~mm}$ granules) for achieving the highest smear density in the finished product. The maximum smear density attained by vibration packed processing only was $\sim 77 \%$ theoretical. An increased density of $82 \%$ was achieved using a mechanical impact processing technique with increased force developed by AECL. Additional density increase to $88 \%$ was achieved by mixing $15 \%$ uranium metal powder with $\mathrm{UO}_{2}$. The metal powder size was $0.25-0.50 \mathrm{~mm}$.

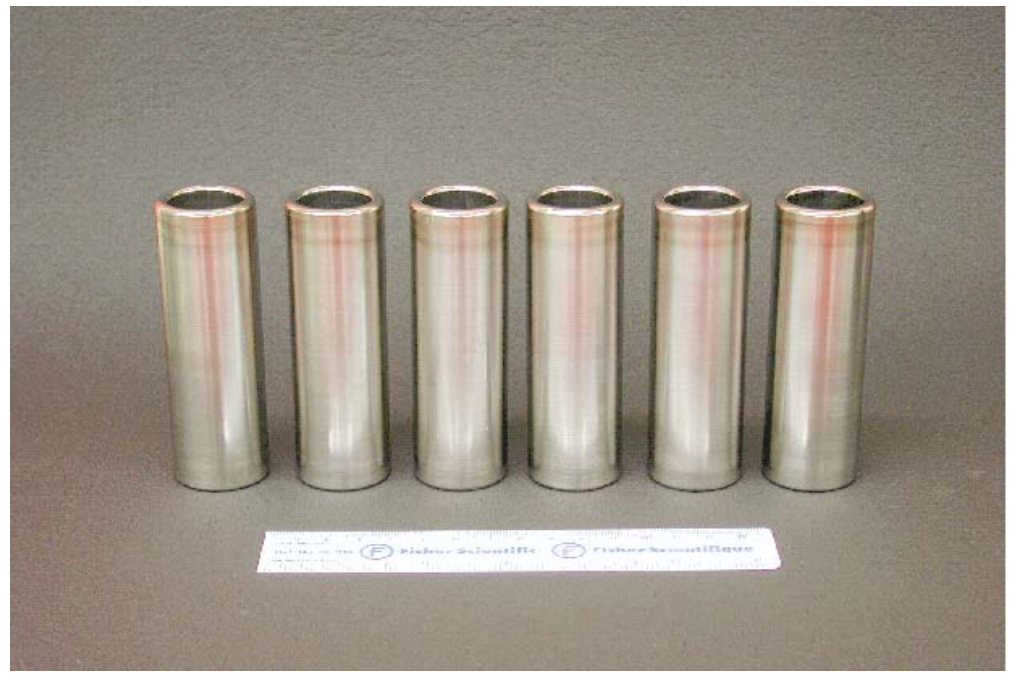

Figure ES-4 Annular fuel specimens for irradiation at MITR

Next, two four foot lengths of annular fuel were manufactured and successfully loaded using the VIPAC approach to achieve a maximum density of $77 \%$ of theoretical. This is insufficient to meet the reference fuel loading requirements of an effective uranium oxide density of at least $85 \%$ of theoretical $\mathrm{UO}_{2}$ density. It was also observed that the granules compacted to a certain density of approximately $72 \%$ relatively quickly and after this point small increases in density were only achieved following extensive compaction. 
Therefore, further exploration of VIPAC fuel was not pursued, but it was noted that higher densities may be achieved through an addition of a uranium metal powder component to the oxide particle fuel mixture before compaction. Hence, VIPAC fuel fabrication route involving addition of metallic uranium powder may be a backup option for the more promising sintered pellet route described below.

Sintered ring pellets for the $13 \times 13$ annular fuel rods were manufactured at the Westinghouse Nuclear Fuel Company in Columbia, South Carolina. Seventy green annular pellets were produced and sixty of these pellets were then sintered. Figure ES-5 shows some of the sintered annular pellets. Properties of thirty sintered pellets were then extensively measured and the OD surface of the pellets were then finished utilizing a commercial centerless grinder. The overall yield of the thirty selected pellets from powder pressing, sintering and OD surface grinding was $97 \%$ with the loss of one pellet during grinding. There were no technical issues with the fuel pellet fabrication or OD surface grinding. The crucial pellet dimensional tolerances met the preliminary fuel design specifications.

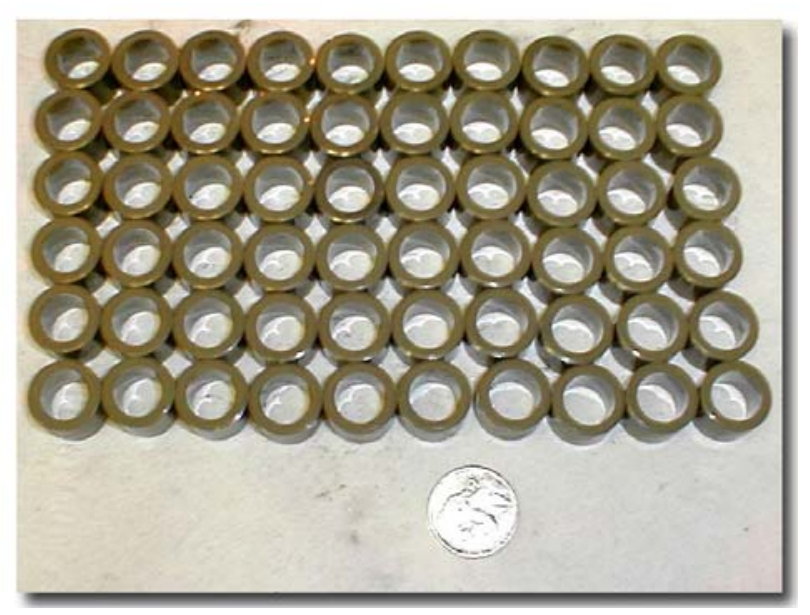

Figure5 Sintered pellets manufactured at Westinghouse

Based on this Westinghouse testing work, the press-and-sinter pellet fabrication route appeared to be the most promising technology for commercially manufacturing the reference annular fuel. Therefore, a second set of annular pellet fabrication and rod loading trials, using commercial fabrication techniques, was arranged by Westinghouse and performed at INVAP (located in S.C. de Bariloche - Río Negro Province, Argentina). The second batch of pellets of about 200 that was produced showed that the desired tolerances can be achieved. The conical shape of the annular pellets has been substantially reduced. Further, end plugs were designed and welding techniques successfully demonstrated. Finally, the 4-foot long rods were successfully loaded with annular pellets and both end plugs welded inside and outside and the rods were pressurized with helium gas.

Overall, the conclusion is that annular fuel elements can be manufactured by commercial fabrication techniques to required specifications using the sintered ring pellet route, at reasonable costs. Therefore, fabrication of annular fuel should not be an inhibiting factor in the commercial introduction of annular fuel to improve the performance of existing light water reactors. The description of fuel manufacturing activities is in Chapter 11. 


\section{Economic Feasibility}

The new fuel could be introduced only if it can bring significant economic benefits to nuclear power plant operators. Therefore, quantification of the potential economic gain is a key goal of this project, so that a separate task was devoted to economic studies.

Fuel cycle cost and the assessment of the impact of the high-power density annular fuel on plant economy were performed by Westinghouse. The objective was to provide the engineering and economic analyses to allow the annular fuel cost/benefit ratio to be determined. The evaluations were pursued in two areas. The first area focused on manufacturing cost, in particular on the modifications required for the Columbia plant to accommodate manufacturing of annular fuel rods and the associated costs. In the second stage, the benefit from a large power uprate on the projected cost of electricity was assessed.

Fuel manufacturing costs were estimated from an assessment of the manufacturing issues encountered when a central tube is introduced in the annulus of a fuel rod. The baseline constraints and assumptions used reflect the current permitting and operational constraints at the Westinghouse Nuclear Fuels plant in Columbia, South Carolina.

Two types of fuel were considered. The first is an annular pellet fuel similar to but bigger than the $\mathrm{UO}_{2}$ based annular pellets currently made for WABA rods at Columbia. The second is a particulate fuel using vibration packing of crushed and screened irregular $\mathrm{UO}_{2}$ particles as has been used by AECL in Chalk River (see Chapter 11) for the test fuel segments.

For annular pellet fuels, the pellets are assumed to be first loaded into the outer tube, as is currently done for solid pellets. This approach is taken since the outside of the pellets can be ground to a very close tolerance. The inside tube is then inserted with a pre-welded bottom closure already attached. The addition of the second tube requires only a minor modification of the current assembly station. The spring and annular closure are then added to the opposite end. Minor increases in manufacturing costs are expected for two new welding stations. The only capital investment is for increasing the sintering furnace capacity due to the lower overall density of the pellets. However, no significant increase in the final cost of fuel is expected, since the pellet cross sectional area does not exceed that of the solid pellets needed in each assembly.

A cost estimate has been made to take into account the following additional capital and additional operating costs due to the manufacture of annular fuel:

1. Product charges for capital costs due to the increased number of sintering furnaces;

2. Product charges for capital costs associated with additional welding stations;

3. Product charges due to increased zirconium usage.

Increases in fuel manufacturing costs were determined from these capital costs and combined with additional zirconium costs to obtain the total marginal cost increase of the annular fuel from the current $\$ .005 / \mathrm{kWhr}(\mathrm{e})$ to about $\$ .00502 / \mathrm{kWhr}(\mathrm{e})$. This cost increase is negligibly small. 
Regarding the benefit on plant economics, three plant options using annular fuel were compared to two options using standard solid fuel. The discounted rates of returns for the various options were found to be as follows (listed best to worst):

1. 1,717 MW(e) Generation III new PWR; annular fuel- $11.3 \%$

2. $1,717 \mathrm{MW}(\mathrm{e})$ Generation III new PWR; standard fuel - $10.8 \%$

3. 1,117 MW(e) Generation III new PWR; annular fuel - 7.3\%

4. 1,117 MW(e) Generation III new PWR; standard fuel- $6.9 \%$

5. $600 \mathrm{MW}(\mathrm{e})$ uprate to a Generation II PWR; annular fuel $-6.3 \%$

The use of annular fuel always improves the rate of return on invested capital. In the case of a new Generation III power plant, the use of annular fuel can be used to either get more capacity from the same sized nuclear island or to reduce the size of the nuclear island. It appears that the rate of return on money can be increased by $0.4-0.5 \%$ if the new annular fuel is used.

For the currently operating Generation II power plants, annular fuel provides a means to significantly upgrade the power output (up to 50\%) using the same nuclear island with new reactor internals, steam generators and circulation pumps, and a new incremental balance of plant (built during plant operation) to handle the increased power production. However, the ROR is less than for the new reactor options. This is mainly due to the high cost of the replacement power and the unused fuel value during the transition from standard to annular fuel. For instance, if these two items were not included, the capital cost would significantly decrease and the value of this option would increase extensively with a ROR of about $11.6 \%$. Therefore, if low cost replacement power is readily available during the transition period and if the unused fuel cost can be reduced due to tighter fuel management before the transition, then the uprate option becomes the most favorable of all options.

Overall, annular fuel appears to be economically attractive in comparison with the solid fuel for any PWR plant. The details of economical studies are given in Chapter 12 .

\section{Fuel Performance}

The performance of the internally and externally cooled annular fuel during irradiation was evaluated using a modeling approach and also a scoping irradiation test at MITR, as outlined in the two sections below.

The FRAPCON-3 code was modified to develop the annular fuel performance code FRAPCON-ANNULAR, which was then utilized to perform analysis of the irradiation of the hottest pin in the sintered annular fuel design. Comparisons have been made with a reference Westinghouse solid fuel rod operating at its rated power, and an actual commercial PWR rod operated to high burnup. The high power annular fuel would be irradiated (in the model) to a much higher burnup than solid fuel ( 86 versus $50 \mathrm{MWd} / \mathrm{kg}$ ). 
At this high burnup, fission gas release (FGR) from the highly uprated annular fuel is larger than the reference solid fuel case in spite of its much lower fuel operating temperature. This is because significant fission gas release starts to occur at burnup higher than $45 \mathrm{MWd} / \mathrm{kg}$ due to microstructure changes of the fuel. However, total FGR from the annular fuel at $86 \mathrm{MWd} / \mathrm{kg}$ is still relatively low (less than $6 \%$ ). Both claddings of the uprated annular fuel experience larger strains during the first hundred days of operation as a result of larger cladding creepdown due to the larger initial diameter, but remain below the $1 \%$ limit. The annular fuel cladding oxide thickness and hydrogen pickup were found to be smaller than for the solid fuel due to lower cladding temperature. At $150 \%$ power, the inner cladding had slightly higher oxide thickness than the solid fuel due to its higher heat flux, but still within acceptable limits. Because the high burnup is achieved at about the same cladding temperature and over the same time period as for today's solid fuel, cladding performance of high power density annular fuel is not significantly different from the reference solid case.

One potential issue identified through modeling is the asymmetry of the outer and inner gap conductances and its effect on the heat flux values, as a result of preferential expansion of the pellet ring towards the outside. A number of approaches have been explored to resolve the issue of this gap conductance asymmetry. A promising approach is adding by sputtering an outer fuel layer of $\mathrm{ZrO}_{2}$ particles. This prevents quick contact between the cladding and the fuel, thus limiting the outer gap conductance due to the presence of a barrier of a smaller thermal conductivity at the time of outer gap closure, if the inner gap is open. After inner gap closure, the $\mathrm{ZrO}_{2}$ at the outer surface is crushed due to a large contact pressure and the outer gap thermal conductance is increased closely matching that of the inner gap. Coverage of $50 \%$ of the outer fuel surface with $\mathrm{ZrO}_{2}$ particles in combination with typical cladding and fuel roughnesses of $3 \mu \mathrm{m}$ was found to yield excellent gap conductance symmetry throughout the entire irradiation period. Moreover, the sintered pellet manufacturing results found that excellent tolerances can be achievable for the annular pellet dimensions, which suggests that the rod can be assembled with a smaller inner gap and the $\mathrm{ZrO}_{2}$ layer sputtering may not be needed. This needs to be further confirmed by irradiation, hence the $\mathrm{ZrO}_{2}$ sputtering technique can serve as a backup.

To simulate fuel performance of VIPAC fuel, the FRAPCON3-ANNULAR(V) code was developed incorporating several new models. These include a new empirical VIPAC thermal conductivity relation as a function of temperature, burnup, porosity and gas pressures; a VIPAC fuel and cladding thermal conductance model based on the original FRAPCON thermal conductance model; a VIPAC fuel-cladding mechanical interaction model and a model of dimensional changes; and an athermal fission gas release model for VIPAC. The performance of the VIPAC fuel was compared to that of the sintered fuel. The results showed that during the first $~ 50$ EFPDs, the VIPAC annular fuel average temperatures were lower than those of the sintered annular fuel in spite of the smaller conductivity of VIPAC fuel, a consequence of the absence of fuel cladding gaps. After the sintered annular fuel gaps close, the fuel average temperature drops below that of VIPAC fuel because of the higher thermal conductivity of sintered fuel. The VIPAC fuel fission gas is predicted to be higher than the sintered fuel $(\sim 12 \%$ at EOL for VIPAC versus $\sim 6 \%$ for sintered fuel) because of the larger surface to volume ratio of VIPAC fuel particles, which facilitates escape of fission atoms by recoil and knock-out. On the other 
hand, VIPAC fuel rod average cladding strains at BOL (when the strains reach maximum values) are substantially lower than those of sintered fuel, because the cladding creepdown during the initial operating period due to external pressure is alleviated. Also, the FRAPCON-ANNULAR(V) results confirmed the expectation of excellent gap conductance symmetry. Design optimization study of annular VIPAC fuel was also performed using FRAPCON3-ANNULAR(V) code. The optimum initial helium (fill gas) pressure was identified to be between 1.4 and $2.0 \mathrm{MPa}$, the optimum particle size yielding the lowest fission gas release was found to lie between $300-600 \mu \mathrm{m}$, and the optimum smear density with respect to low fission gas release, low EOL rod pressure and small cladding strains was identified to be in the range of $85 \%-90 \%$. Fuel performance models and the results are discussed in Chapter 13.

Regarding the irradiation tests of VIPAC fuel, only limited irradiation experiments could be performed because of time and funding constraints of this project. Since there is much more extensive experience with behavior of the sintered pellets than with VIPAC fuel, only VIPAC fuel was selected for irradiation tests. The goal of the irradiation experiment was to obtain data on fission gas release and potential irradiation induced dimensional changes, which could occur early during irradiation (note that no temperature driven sintering is expected due to very low fuel temperatures).

Two of the VIPAC annular fuel samples manufactured by AECL shown in Figure ES-4 were instrumented with thermocouples and assembled into irradiation capsules. Reactor coolant at $50^{\circ} \mathrm{C}$ was used for cooling. This required the design of special irradiation capsules that provide additional heat transfer resistance between the coolant and cladding to match the cladding and fuel temperatures to those predicted during PWR operation. This has been accomplished through a lead-bismuth eutectic filled gap. The seal welded and pressure tested capsules were inserted into the MITR-II core, as shown in Figure ES6. The two assembled capsules were irradiated to a burnup of 6.9 and $5.7 \mathrm{MWd} / \mathrm{kg}-\mathrm{U}$ over the period from March to September 2004. Linear heat generation rates in the fuel samples were near those that would be experienced in a peak rod at 150 percent of current PWR power density. After the irradiation was stopped, the fuel samples were transferred from the core to the fuel storage ring in the reactor for radiation decay before post irradiation examination (PIE).

The PIE, which was performed in August 2005, confirmed that predicted burnups were within several percent and showed lower than predicted fission gas release. Fission gas release was evaluated by comparing the integrated counts for the Kr-85 $514 \mathrm{keV}$ peak in the fuel to the integrated counts in the plenum region, and assuming that all released fission product gas has migrated to the plenum. About $0.5 \%$ fission gas release was estimated for each capsule. These values are subject to fairly large uncertainty because the $514 \mathrm{keV}$ peak is close to the $511 \mathrm{keV}$ annihilation peak and is not fully resolved from it. However, it is very likely that the actual fission gas release is not more than several per cent of the fission gas generated.

The details of irradiation program and the results are summarized in Chapter 14. 


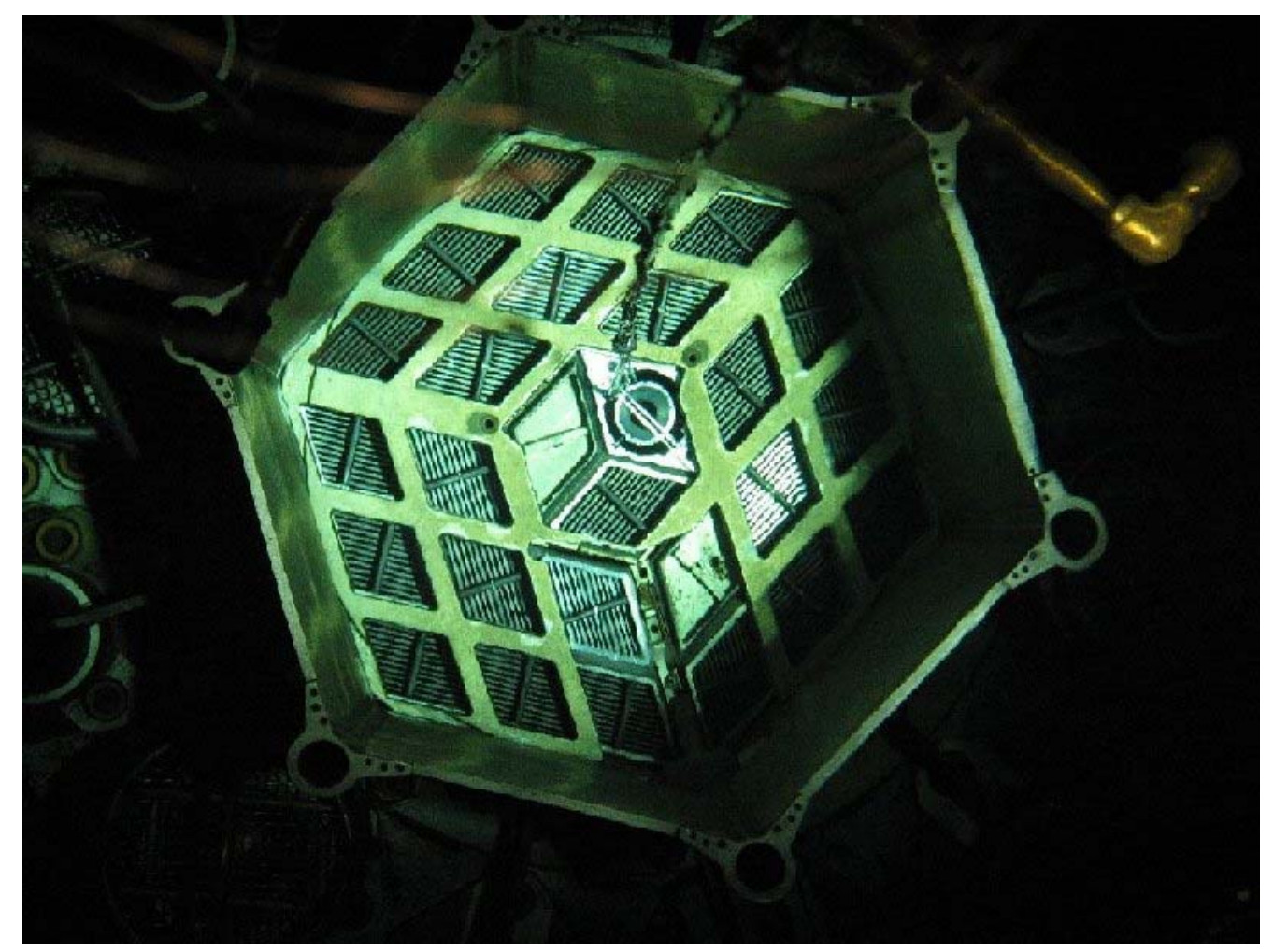

Figure ES-6 Top view of MITR core with loaded annular fuel 